\title{
Frequency of Attendance and Interaction of Students in 3D Multi- User Virtual Environments (MUVEs): The Effect on Learning English Language
}

\author{
Dr. Muhammad Saleem Khan \\ Coordinator English Language Programme, Buraydah Community College \\ Qassim University, Saudi Arabia \\ Dr. Samy Abdelwahab Safaan \\ Consultant Deanship of e-learning Qassim University, Assistant Professor Computer Sciences, \\ Nile Higher Institute for Business Technology in Computer Sciences; Certified Trainer for \\ National E-Learning Centre and Distance Learning, Saudi Arabia
}

\begin{abstract}
This research study of third-dimensional multi-users virtual environment is experienced at Buraydah community college, Qassim University by the Saudi EFL students of level three in their Computer Assisted Language Learning course. In this paper the personal presence of the participants and their frequency of interaction are investigated. The English language laboratory was used to provide $3 \mathrm{D}$ multi-users virtual environment to the participants by awarding each of them an avatar character of their own choice. These were designed to practice and improve the proposed speaking skills of English language as a foreign language. This environment provides the participants to concentrate on their speaking skills to improve it by collaboration, participation, and frequent interactions. The results from such multi-users virtual social interactions showed a positive academic success of the participants in the current study. In Saudi culture, the language students have least interaction for improving their spoken skills of English where a 3D multi-users interaction is recommended for success of spoken English.
\end{abstract}

Keywords: Computer Assisted Language Learning (CALL), Saudi EFL students, thirddimensional virtual environment

\section{INTRODUCTION}

The advancement in technology is greatly observed in twentieth century. This era is proved to be of technological advancement in the life of human. In this century, various improvement has been done in regards to food, warfare, trade, medicine, dresses, equipment, electronics, etc. The advancement was possible by educational research and development (Hismanoglu, 2012). The diverse learning prospects, which include virtual environments and internet, have increased the capabilities of learning in students. This is not only seen in general education, but it is also helps in learning foreign language easily. It has also played a vital part in changing the concept of education from traditional learning to virtual learning. It has been observed that there is an incredible increase in regards to higher education sector. This is done because of the creation of variety of educational technologies, which include educational and information technologies (Gajňáková, Vaculík \& Vaško, 2010). This advancement has made enormous increase regarding enrollment of students all over the world. This is helpful in getting the educational programs and degrees, as virtual learning by distance got no geographical boundaries. 
Today, it has been observed that the people are who are not able to accomplish their life long desire regarding their educational career. The online education technologies and virtual learning atmosphere has proved to be academically more successful and motivating for them in comparison to traditional one. This is because educational technologies are more accessible, flexible and inclusive. Buraydah Community College (BCC); Saudi Arabia, is one of such leading colleges of Qassim University which provides additional courses of e-learning to its students in all programs such as diplomas in Computer Sciences (CSs), Human Resources Management (HRM), English as Foreign Language (EFL) etc.

\section{RESEARCH QUESTIONS}

The study aims to research following questions:

1. To explore effectiveness of learning applications on 3D Second Life for the prospective foreign language pre-service teachers of Qassim University.

2. How effective 3D multi-users virtual environment is to enhance the speaking skills of EFL students.

\section{PURPOSE OF STUDY}

Very few studies look into the use of 3D VLEs for teacher education, training and development, let alone foreign language teachers. Some European Union projects have attempted to do so. For instance, AVALON Project (2009/2011) aimed at "creating and piloting a training course for teachers who would like to extend their teaching skills to include working in virtual worlds". Another Project looking at this field is ASSIS (2011) funded by Umea University in Sweden. The Project "makes use of the affordances offered by Second Life in order to raise sociolinguistic language awareness among teacher trainees and other students studying courses in sociolinguistics". (Ibanez, Garcia, Galan, Maroto, Morillo \& Kloos, 2011).

The AVATAR Project (2009/2011) supported by European Union "provides an opportunity for both teachers and students to benefit from ICT skill development, social learning opportunities and a resource to help revive the traditional classroom environment, adding value to the learning process". Another European Union Project "Euroversity Project" (2011/2014) tries to find out ways to bring together teachers, professionals and institutions across Europe to use modern VLEs and contribute to the modern language education (Ibanez, Garcia, Galan, Maroto, Morillo \& Kloos, 2011).

The recent European Union "CAMELOT Project" (2013/2015) also targets language teachers by providing teacher training course to equip teachers with 21st century digital skills necessary to record machine and create their own ad hoc materials in 3D VLEs (Ibanez, Garcia, Galan, Maroto, Morillo \& Kloos, 2011). The field was investigated for example studies from Turkey, and one such study was observed from Middle East Technical University as part of MA study in Computer and Instructional Technologies Department and students were asked about their opinions about the SL.

With the grant a station computer, to conduct the lessons, and place on Second life was rented. The SL location was Plot 12 on Education III. This place was selected deliberately on the potential it had for education as it is hosting universities, like Free University of Berlin and Dublin University, from around Europe in November 2012. The teacher of the class and technical staff was made acquainted with the environment first and teacher and the technical staff of the project collaborated in designing the classroom for the students. The Computer lab of Faculty was secured for those students who might want to join but have no access facilities on their own. Couple of Project meetings was done on the plot to 
gather experience and observe the possible problems and solutions (Ibanez, Garcia, Galan, Maroto, Morillo \& Kloos, 2011).

\section{LITERATURE REVIEW}

Chen (2016). has observed that recently distance education has given a new platform for learning i.e. multi-users virtual environments (MUVEs) which provides students with an interactive three-dimensional learning environment. There are dynamic benefits out of the new trends in virtual environments. Virtual worlds give active response, real time option for individualized learning \& investigation, and analysis Susan (2011). 3D virtual trends have multi users' instructional uses, e.g. social interaction, creation of a strong media environment, presenting prospects for social interaction and community formation. It has also play an imperative role in paving the way for assistance, maximizing a sense of shared presence, dissolving societal boundaries, lessening social anxiety, increasing students' inspiration and involvement, and cooperative millennial generation learning inclinations (Wang,Burton \& Falls, 2012; Susan, 2011; Shih \& Yang, 2008; Rahimi, Golshan \& Mohebi, 2014).

The virtual world has become an established reality tool in the field of didactic \& pedagogic literature. The benefits of 3D MUVEs as instructional implements are frequent interactions or participation, creative skills, mutual coordination (Garcia-Ruiz, Edwards, Aquino-Santos, \& ElSeoud, 2008), and active presence, motivation, individualization, and high frequency of interaction (Varli, 2009). In other words, quests have widely been used in language learning (Chen, Doong, \& Hsu, (2014), as second or a foreign language needs a natural environment for it acquisition. The third dimensional virtual worlds are now being used massive in entertainment after its use in education for a number of years due to spread of information and educational technologies. It has been displayed in the current study of the paper that how virtual world is transformed into a 3D virtual learning environment for learning a foreign language. The multi-user virtual worlds exist since 1970s; dependent, in the beginning, on text descriptions only of the world and actors in it (Aydin, 2013). The users were enabled to modify and extend virtual world after the creation of MUD (Multi-User Dungeon) which later on was renamed as MUD Objects-Oriented (MOOs). It has been observed that with the passage of time several educational projects were developed like text-based virtual worlds to help teachers, students and working community for their intellectual development and knowledge sharing or for teaching ranging from language to computer sciences (Garcia-Ruiz, Edwards, AquinoSantos \& El-Seoud, 2008).

In fact, 3D virtual learning environment is an application of Computer Assisted Language Learning (CALL). The 3D VLEs are actually computer enhanced displays which allow and compel the users' to feel being present in an environment other than the real ones, and interact in the virtual environment (Garcia-Ruiz, Edwards, Aquino-Santos \& El-Seoud, 2008). Varli (2009) further elaborates that most of the famous 3D Multi-user Virtual Environments (MVLEs) is the Second Life (SL); as more than 36 million people have opened up their accounts in virtual worlds.

Therefore, the participants in the VEs create an identity of their own in the shape of an avatar (Chen, Doong \& Hsu, 2014). The participants can even choose, change, and develop the form, shape or appearance by themselves and hence individualizing the learning experiences (Hismanoglu, 2012). This type of learning environment increases the learning motivation (Gajňáková, Vaculík \& Vaško, 2010). Resultantly, the participants involves in taking risks while actively participate in the learning of a foreign language (Chen, 2016). 


\section{Sloodle Menu \\ Your avatar: \\ Buddy Sprocket}

足 My Sloodle profile

Object Distributor

$\cdot \rightarrow$ Login Zone

N User Management

* Sloodle Configuration

固 Notecard Setup page

Sloodle Menu Version: 0.21

Sloodle Version: 0.21

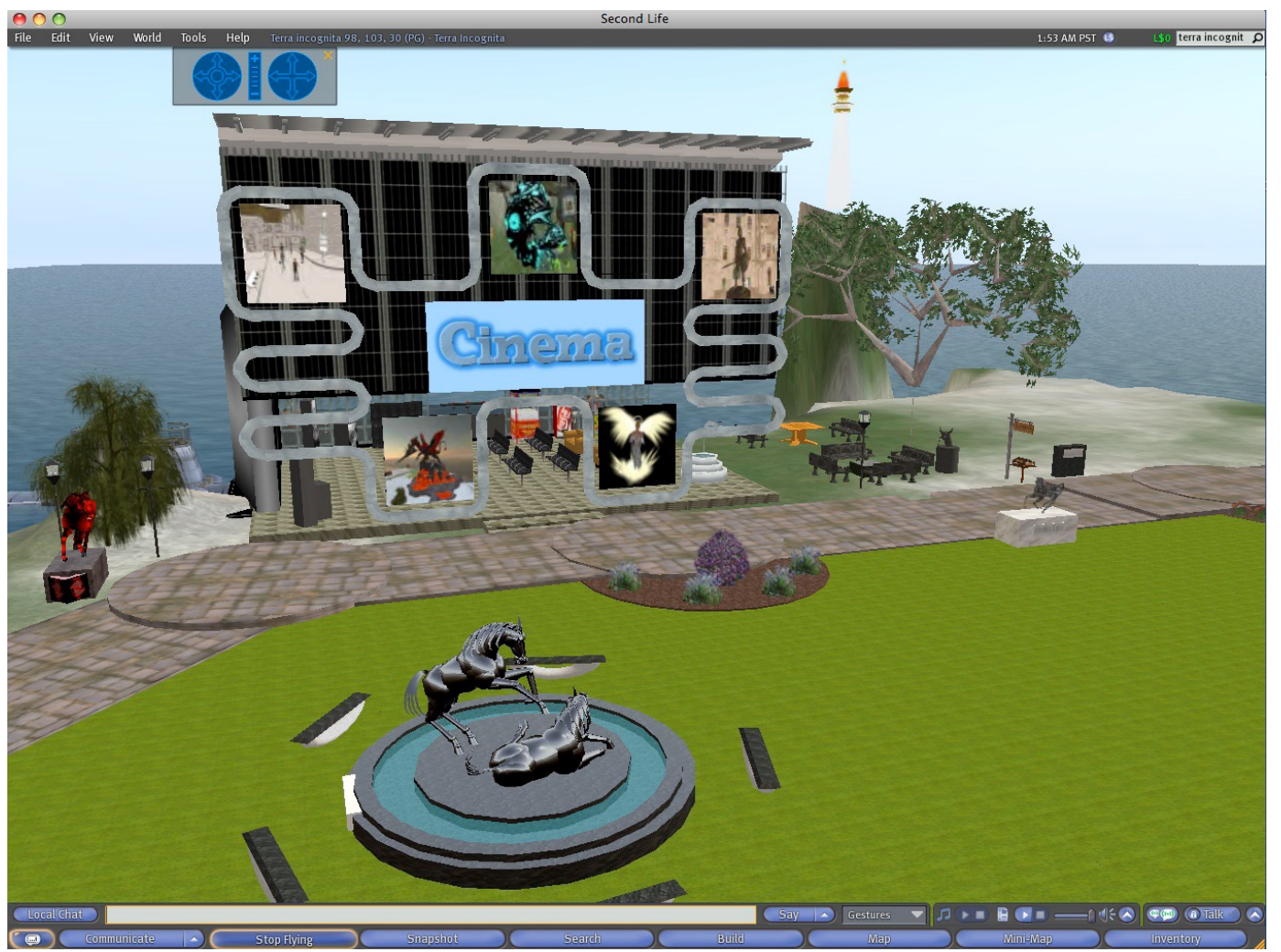




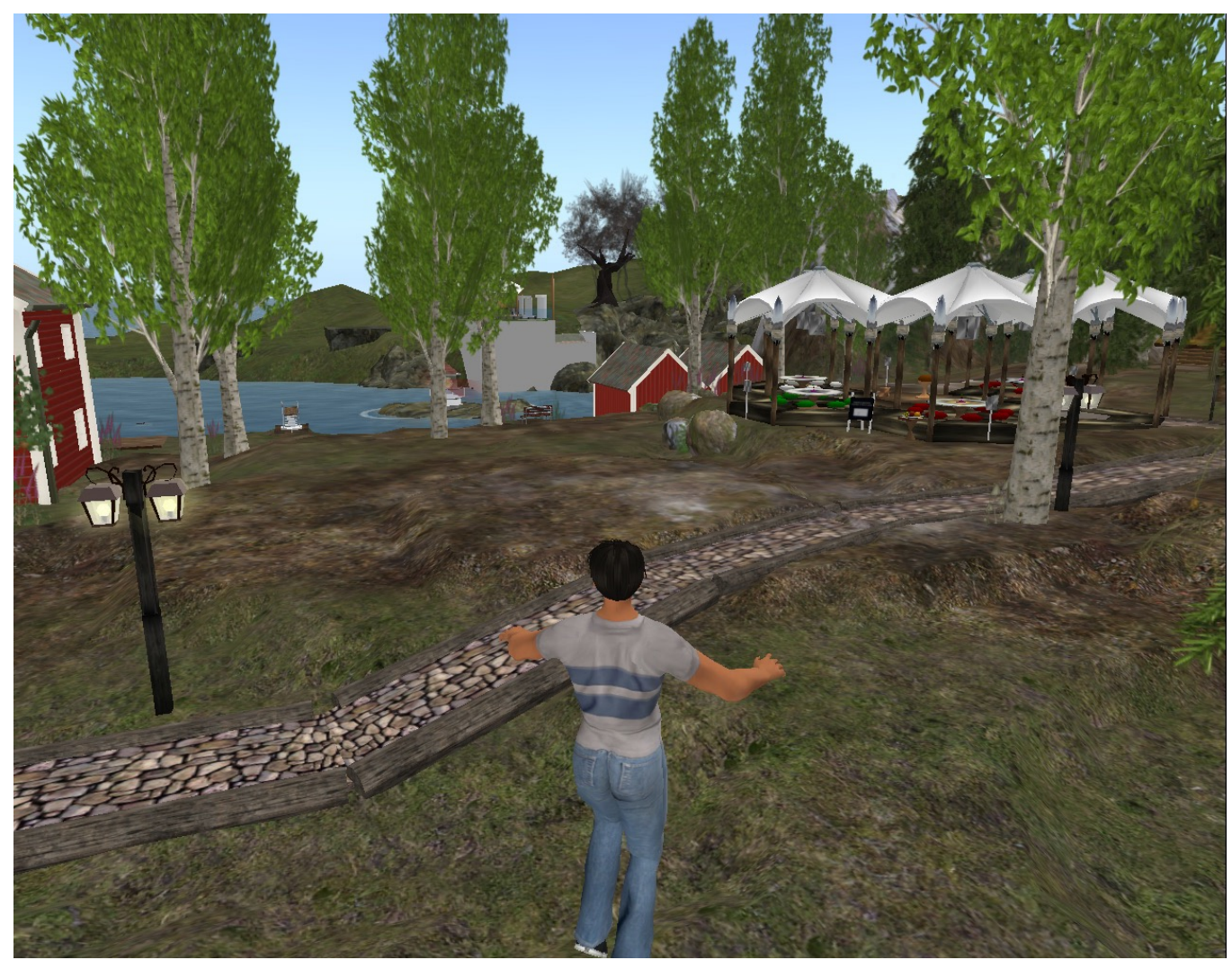

The 3-D VLE is owned, developed, constructed and changed through the "objects and content, which are establish by the learners" (Wang, Burton \& Falls, 2012). It has been observed that learners are provided with the freedom in order to design their environment by themselves. They can construct and design the atmosphere by collaborating various determined scenarios. They are required to own what they have created and develop the knowledge through free will. This would help learners to relate their own objects, content and other fellow learners. They would enable them to become more independent and active in the process of learning (Susan, 2011). Therefore, learners would attend the autonomy through having opportunity in order to decide on objects, knowledge and design and what has been developed in the process regarding learning. It is believed that learners would be immersed in this environment, which cater the realistic feelings regarding opportunity of interaction and presence (Rahimi, Golshan \& Mohebi, 2014).

Since the late 1970s, it has been observed that online multi-user virtual worlds has been established. They were initially based on the text descriptions regarding the world and the actors in it (Garcia-Ruiz, Edwards, Aquino-Santos, \& El-Seoud, 2008). After the evolution of first Multi-User Dungeon (MUD) and its later modification as MUD Object-Oriented (MOOs) has developed the ability in user to modify and extent the virtual world. In the past few years, variety of educational projects were developed by using the text-based virtual worlds in order to support students. These development also support workplace community development, sharing knowledge and for teachers to use in teaching subjects from traditional to computerscience (Ibanez, Garcia, Galan, Maroto, Morillo, \& Kloos, 2011).

In regards to the recent years, IVWs has been remained as fringe activities for both serious and entertainment use employed or enjoyed by a small audience as well. However, the contemporary picture presented is somewhat different, the Massively Multi-Player Online Games (MMOGs) now unassailable for user base in the tens of millions (Garcia-Ruiz, Edwards, 
Aquino-Santos \& El-Seoud, 2008). The interest regarding the use of IVWs for education has been booming. The current survey presented by Eduserv Foundation identified that nearly half of the UK higher education institutions have developed some kind of activity or presence in second life (Chen, Doong \& Hsu, 2014). However, few IVWs are designed particularly to support the educational objectives.

In considering, the early use of worldwide web in regards to education serve as a corollary example. The large-scale adoption in regards to the web-based e-learning needed the establishment of VLEs. It helps in supporting and simplifying the learning, instructional, communication, assessment and common management tasks that are used in e-learning (Lan, 2015). It has been observed that without developing the environments for education, it is the most challenging task for the educators to effectively deliver and employ web in e-learning (Rahimi, Golshan \& Mohebi, 2014).

A VLE (virtual learning environment) is considered a system design, which support learning and teaching in educational setting. VLE works normally over the internet and it provides the collection of tools, which include uploading content, organizing and collecting students' grades, communication, questionnaires, assessment, return of student work, tracking tools, administration of group of students and peer assessment. (Chen, Doong, \& Hsu, 2014). The example include Virtual Campus and Second Life. It has been observed that VLEs are used in educational settings in order to make the learning.

\section{Second Life in EFL}

SecondLife is a wonderful online toolkit. You can use it for a multitude of collaborative online creative activities. I have friends who build castles, make clothing, play music, tell stories, perform in plays, make movies and do dozens of other things. It is a unique approach to virtual world development is the ability to collaboratively edit user-generated content in a visually contiguous environment. All 3D digital content carries an intelectual property license, which allows content creators to share it with others for free or to charge a small fee for personal usage.

The educators of foreign language have used various kinds of game focused virtual technologies. After the launch of SL, researchers believed that virtual reality played an imperative part in promoting the foreign language learning. It is observed that Second Life showed five aspects in regards to foreign language learning, which include peer teaching in student-centered learning, prominence of play and experimentation, natural content and communication, student work as a researcher and individual learning (Wang, Burton \& Falls, 2012).

SL is a multi-user created cyber environment that allows the people all over the world to perform the social interactions. The learning curve of Second Life is considered high. This is not just the cumbersome interface. As a very complex socio-economic environment, there is really a lot to learn before one can thoroughly enjoy it. As such, its complexity is often quoted as a reason for the low amount of users. It is used for communication for various purposes, such as education, commerce and business. This virtual environed. Would help students in providing the interactive and immersive real life communications. It contributes in developing the great benefits regarding foreign language education. It is believed that SL has opened the new dimension to the study of second language (Gajňáková, Vaculík \& Vaško, 2010). 
The process of SL has provided two ways of communication, which are text, based chat and live voice chat. The communication can be done individually or in a group format. It provides user to interact with each other verbally in real time. In regards to the communication other than the text based or voice, chat users can also interact by showing non-verbal gestures, such as thumbs-up or waving. Second Life is targeted towards adults, although minors have restricted access to several areas. One significant characteristic about Second Life is that privacy is a standard feature, and revealing other people's real life data is actually forbidden and cause for banning. All users are, by default, pseudonymous, but are allowed to reveal as much or as little as they want from their real lives. Posting chat transcripts without permission is also forbidden one of many community rules that ensure that drama levels remain as low as possible and privacy is held as a standard by all. This kind of communication development would help the teacher of foreign language learning in establishing the interactive and appealing learning. This would help learners in practicing, hearing and deploying the target learning. In regards to the learning objectives, second life can be structured in a way that illustrate context with specific language learning topics (Wang, Burton \& Falls, 2012). It can be displayed through the welldesigned graphics and have a colorful objects in order to meet the needs. In the past few years, it has been observed that SL has played an essential part in providing EFL an effective platform (Shih \& Yang, 2008).

\section{METHODOLOGY}

The method used in this study is descriptive. Moreover, a mixed model, in which quantitative and qualitative research techniques are used. Therefore, the triangulation of the data collected has been aimed. The study group comprises of Qassim University Hasan Ali Yücel Faculty of Education English Language Teaching Department Senior students. Earlier the study, learners were given pre-test about readiness for online/distance learning and inflict the idea of 3D VLEs. After the completion of the class, the pre-service teachers were given a questionnaire asking for their opinion about the experience in the virtual world and open-ended questions to reflect on their experience. 36 English Language Teaching Department Students and participated in the initial test, 16 Female and 10 male students answered the Interview questions.

In regards to 3D learning scenario, all the activities are designed as interactions of avatars with 3DVWs elements, which include 3D objects, synthetic environment, NPCs and other avatars. All these elements are designed to practice and it develop skills, which are involved in learning the foreign language.

\section{Reading Skills}

They are promoted with the help of information, which is tagged in 3D objects included in the setup. When one of the object is selected, the name is appeared with practical material (reading comprehension). For example, the associated street names were written, which were anecdotes regarding events, which is occurred there at the time of Velázquez.

\section{Listening Skills}

They are encourage by interaction with 3D objects and NPCs. Few of the 3D objects are linked with audio, which is triggered when the learners approach the object. For example, linked with the statue of Velázquez is a speech in regards to its major paintings. Learners are also required to hear pre-recorded conversations between the NPCs. It has been observed that simple conversations helps in illustrating the use of more complex conversation and grammar patterns that are linked to the cultural aspects. It helps in developing the more advanced listening skills. 


\section{Writing Skills}

It will help learner to develop the basic writing skills by using the grammar and vocabulary of the lesson to give and ask information to NPCs, which understands the simple constructions. This process is done through using natural language processing Chabot's (Wang, Burton \& Falls, 2012).

\section{Speaking Skills}

These skills are developed by variety of activities that are previously described. These are achieved mainly through exploration of virtual environment. All learners discover similar vocabulary and patterns of language. However, not all learners are able to achieve similar information regarding Velázquez. The learners were divided in the groups; each group will be able to hear some of the dialogues that are played through NPCs (Gajňáková, Vaculík \& Vaško, 2010). Learners will exchange the information they have received among them, this would help in passing collaboratively a final test.

\section{RESULTS AND DISCUSSION}

The results indicates that $96 \%$ students who participated in the study stated that they own a computer and $95 \%$ of them asserted that they have an access to internet at home. The frequency table below shows the result

Table 1: "how much were you able to control the events?"

\begin{tabular}{lcc}
\hline & f & $\%$ \\
\hline Never & 0 & $0 \%$ \\
Rarely & 5 & $14 \%$ \\
Sometimes & 3 & $7 \%$ \\
Often & 26 & $71 \%$ \\
Always & 3 & $7 \%$ \\
\hline
\end{tabular}

The results shown in table indicates that only $14 \%$ of the students shown that they have problems in regards to control the events in environment. Rest of the students have shown that do not have any problem. However, when the students were asked that how responsive was there environment in regards to the actions they have initiated. Around $79 \%$ answered as often and $14 \%$ answered as always.

Table 2: "How natural did your interactions with the environment seem?"

\begin{tabular}{lcc}
\hline & f & $\%$ \\
\hline Never & 0 & $0 \%$ \\
Rarely & 3 & $7 \%$ \\
Sometimes & 5 & $14 \%$ \\
Often & 28 & $79 \%$ \\
Always & 0 & $0 \%$ \\
\hline
\end{tabular}

As the results in table 2 shows that majority of students persists that their interactions with environment seems to be natural. 
Table 3: "How completely were all of your senses engaged?"

\begin{tabular}{lcc}
\hline & f & $\%$ \\
\hline Never & 0 & $0 \%$ \\
Rarely & 0 & $0 \%$ \\
Sometimes & 5 & $14 \%$ \\
Often & 26 & $71 \%$ \\
Always & 5 & $14 \%$ \\
\hline
\end{tabular}

In accordance to the table 3, it shows that senses of students are pretty engaged. Around $64 \%$ of the students has identified that their senses are often engaged to visual aspect of environment and $21 \%$ of the students indicate that it always involve them.

Table 4: "How compelling was your sense of objects moving through space?"

\begin{tabular}{lll|}
\hline & f & \\
\hline Never & 0 & $\%$ \\
Rarely & 15 & $0 \%$ \\
Sometimes & 18 & $43 \%$ \\
Often & 3 & $50 \%$ \\
Always & 0 & $7 \%$ \\
\hline & & $0 \%$ \\
\hline
\end{tabular}

Majority of the participants of the study stated that sense of objects, which were moving in space was not compelling. However, around $50 \%$ of the participants declared that the information coming from variety of senses is compelling.

Table 5: "How much did your experiences in the virtual environment seem consistent with your real-world experiences?"

\begin{tabular}{lcc}
\hline & f & $\%$ \\
\hline Never & 0 & $0 \%$ \\
Rarely & 3 & $7 \%$ \\
Sometimes & 5 & $14 \%$ \\
Often & 23 & $64 \%$ \\
Always & 5 & $14 \%$ \\
\hline
\end{tabular}

In accordance to the results shown in table 5, around $78 \%$ of the study participants have stated that their experience in virtual environment was consistent with their real world experiences as always and often. Nearly $64 \%$ of the participants asserted that the sounds, which were coming from outside environment were significant.

Moreover, around 85\% of the participants verbalized that they could actively research and examine the environment through using visuals and $79 \%$ stated that they could be able to search virtual environment actively through touching. 
Table 6: "How well could you move or manipulate objects in the virtual environment?"

\begin{tabular}{lcc}
\hline & f & $\%$ \\
\hline Never & 5 & $14 \%$ \\
Rarely & 10 & $29 \%$ \\
Sometimes & 18 & $50 \%$ \\
Often & 3 & $7 \%$ \\
Always & 0 & $0 \%$ \\
\hline
\end{tabular}

Table 7: "How involved were you in the virtual environment experience?"

\begin{tabular}{lll|}
\hline & f & $\%$ \\
\hline Never & 0 & $0 \%$ \\
Rarely & 0 & $0 \%$ \\
Sometimes & 8 & $21 \%$ \\
Often & 15 & $43 \%$ \\
Always & 13 & $36 \%$ \\
\hline
\end{tabular}

Majority of the participants in the study have shown that they have been involved in virtual environment experience.

Table 8: How proficient in moving and interacting with the virtual environment did you feel at the end of the experience?"

\begin{tabular}{lcc}
\hline & f & $\%$ \\
\hline Never & 0 & $0 \%$ \\
Rarely & $\mathbf{3}$ & $\mathbf{7 \%}$ \\
Sometimes & $\mathbf{8}$ & $\mathbf{2 1 \%}$ \\
Often & $\mathbf{2 6}$ & $\mathbf{7 1 \%}$ \\
Always & $\mathbf{0}$ & $\mathbf{0 \%}$ \\
\hline
\end{tabular}

Around $71 \%$ of the participants in the study felt proficient in regards to interacting and moving with the virtual environment in the end of the experience.

Table 9: "How well could you concentrate on the assigned tasks or required activities rather than on the mechanisms used to perform those tasks or activities?"

\begin{tabular}{lcc}
\hline & f & $\%$ \\
\hline Never & 0 & $0 \%$ \\
Rarely & 0 & $0 \%$ \\
Sometimes & 13 & $36 \%$ \\
Often & 21 & $57 \%$ \\
Always & 3 & $7 \%$ \\
\hline
\end{tabular}

$36 \%$, of the participants stated, that they sometimes concentrate on the tasks assigned or the activities needed rather than the mechanisms used in order to perform those activities and tasks. $57 \%$ of the participants stated as often and 7\% stated as always. Moreover, $64 \%$ of the participants also stated that they have learn new techniques, which has altered their performance. 
The results obtained from the interview questions provide the additional information regarding virtual environment and second life. Participants gives different views in regards to the experience they had in second life. On asking them the most interesting part of SL (second life), variety of answers were given. Few of the participants stated that they faced difficulties regarding the sound and speaking, as all avatars were speaking at same time. However, many stated that it was good experience. Through this, they were able to meet their old friends. Classmates who have not talked in class ever, ask questions to each other on SL.

On asking the duration to get in second life platform, majority of respondents stated that it took 1 or 2 weeks to learn second life platform. Whereas, few of the respondents stated that it did not took mush time to learn second life platform. The responses on asking how natural or real was the environment of SL, majority of them stated that it looks like the real world and they find it enjoyable. Moreover, they stated that they were not interacting face-to-face so they speak as relaxed.

The question regarding the effect of SL on learning provides various views of the respondents. Majority of the respondents stated that it was the positive move. Because of SL, they were able to learn new vocabulary. Moreover, they stated that this activity has increased their level of confidence. One of the respondent stated that "Positive, because it allows students to use multiple senses, diverse materials, and to be active and autonomous in the classroom."

On asking that in what other ways SL could be used, respondents stated that it should be used for various listening activities. Furthermore, they stated that SL could be used in giving lectures and in meetings. Through this introduction of the lesson can be given. Whereas, few stated that with the help of SL off-campus events should be organized for students.

\section{CONCLUSION}

It is believed that integrating technology in the field of education is a challenging task, as it is influenced through several of factors. In accordance to the findings of the research, it is identified that it is not highly compelling to move around the virtual environment. Majority of the participants in the study believed that they could actively use environment by touching. In the study, $79 \%$ of the participants that the interaction done through second life is natural. In regards to the 3D visuals environment, the involvement of students are achieved to 85\%. Whereas, $64 \%$ of the participants in the study has observed that the experiences they had on virtual environment seems to be consistent with the experiences of real-world. Moreover, the study highlights that majority of the participants in the study have shown their interest in virtual environment and they have shown high involvement. However, students have faced technical problems while using second life, but they easily learn how to handle.

The successful integration of technology in the field of education is not just using the computer in the classrooms. It has involved the transformation of what has done and students are prepared for learning in the technologically erudite learning environment. However, second life (SL) is believed to be an impressive instrument for educational environment. It has been observed that for EFL students second life can be used in a cost-effective manner. With the help of this, they will be able to immerse themselves and can have access to multimodal features in order to gain the visual support. Nonetheless, more practical and theoretical research on the task-based interaction in second life is still required before making the positive claims that SL would create the difference in EFL learners' language acquisition. 
Khan, M. S., \& Safaan, S. A. (2017). Frequency of Attendance and Interaction of Students in 3D Multi-User Virtual Environments (MUVEs): The Effect on Learning English Language. Advances in Social Sciences Research Journal, 4(6) 91-102

\section{References}

Aydin, S. (2013). Second Life as a Foreign Language Learning Environment: A Review of Research. Turkish Online Journal of Distance Education-TOJDE. Retrieved from http://files.eric.ed.gov/fulltext/EJ1006247.pdf

Chen, J. (2016). EFL learners' strategy use during task-based interaction in Second Life. Australasian Journal of Educational Technology. retrieved from

https://www.google.com/url?sa=t\&rct=j\&q=\&esrc=s\&source=web\&cd=\&ved=0ahUKEwiM6c_ayd_RAhXsDsAKHY mRAlAQFgg8MAI\&url=https\%3A\%2F\%2Fajet.org.au\%2Findex.php\%2FAJET\%2Farticle\%2Fdownload\%2F2306 \%2F1346\&usg=AFQjCNHSjj1bNlk3QRCFah4cOvKrji7KRw\&bvm=bv.145063293,d.ZGg

Chen, Y.L., Doong, J.L. \& Hsu, C.C. (2014). EFL learning scenarios: Effectiveness of using 3D virtual reality. In M. Searson \& M. Ochoa (Eds.), Proceedings of Society for Information Technology \& Teacher Education International Conference 2014. Retrieved from http://www.learntechlib.org/noaccess/130912

Gajňáková, M, Vaculík, J \& Vaško, M. (2010). The use of multi-user virtual environments in the field of education. Reliability and Statistics in Transportation and Communication. Retrieved from http://www.tsi.lv/sites/default/files/editor/science/Publikacii/RelStat_10/sess_5_gajnakova_vaculik_vasko.pdf

Garcia-Ruiz, M.A., Edwards, A., Aquino-Santos, R ., \& El-Seoud, S.A. (2008). Collaborating and learning a second language in a Wireless Virtual Reality Environment. Int. J. Mobile Learning and Organisation Guinn CI. Retrieved from

http://www.sciencedirect.com/science/article/pii/S1877042814038014?np=y\&npKey=312d2396d93ceea37f44 31e33dd99e4d01cf3db0224836cdd737fe36ff501ecb

Hismanoglu, M. (2012). Integrating second life into an EFL classroom: A new dimension in foreign language learning and teaching. International Journal on New Trends in Education. Retrieved from http://www.ijonte.org/FileUpload/ks63207/File/09.hismanoglu.pdf

Ibanez, M.B., Garcia, J.J., Galan, S., Maroto, D., Morillo, D. \& Kloos, C.D. (2011). Design and Implementation of a 3D Multi-User Virtual World for Language Learning. Educational Technology \& Society. Retrieved from http://www.sciencedirect.com/science/article/pii/S1877042814038014?np=y\&npKey=312d2396d93ceea37f44 31e33dd99e4d01cf3db0224836cdd737fe36ff501ecb

Lan, Y. (2015). Contextual EFL learning in a 3D virtual environment. Language Learning \& Technology. Retrieved from http://llt.msu.edu/issues/june2015/action.pdf

Rahimi, A, Golshan, N \& Mohebi, H. (2014). Virtual Reality as a Learning Environment in Iranian EFL Context: Personal, Technical, and Pedagogical. Elsevier B.V. Retrieved from http://www.sciencedirect.com/science/article/pii/S1877042814038014?np=y\&npKey=312d2396d93ceea37f44 31e33dd99e4d01cf3db0224836cdd737fe36ff501ecb

Shih, Y \& Yang, M. (2008). A Collaborative Virtual Environment for Situated Language Learning Using VEC3D. Educational Technology \& Society. Retrieved from http://ifets.info/journals/11_1/5.pdf

Susan, G. (2011). Communication Strategy Use: An Exploratory Case Study of an EFL Lesson in Second Life. Edinburgh Research Archive. Retrieved from https://www.era.lib.ed.ac.uk/handle/1842/6101

Varli, O. (2009). Three-Dimensional (3D) Virtual Worlds through ESL/EFL Teachers' Perspectives in Second Life. University at Albany, State University of New York. Retrieved from http://home.ku.edu.tr/ ovarli/docs/Master's\%20Thesis.pdf

Wang, F., Burton, J \& Falls, J. (2012). A Three-Step Model for Designing Initial Second Life-Based Foreign Language Learning Activities. MERLOT Journal of Online Learning and Teaching. Retrieved from http://jolt.merlot.org/vol8no4/wang_1212.pdf 